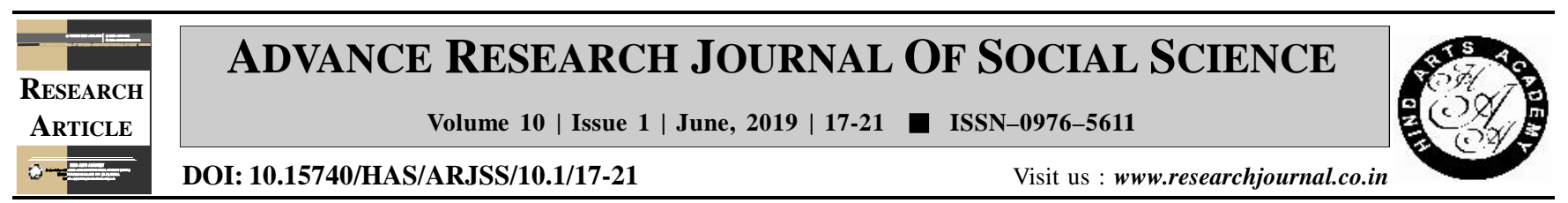

\title{
Status of mental health amongst college going youth of Udaipur district, Rajasthan
}

Prerna Gupta* and Gaytri Tiwari

Department of Human Development and Family Studies, College of Community and Applied Sciences, Maharana Pratap University of Agriculture and Technology, Udaipur (Rajasthan) India

(Email : guptaprerna404@gmail.com, Tiwarigaytri@gmail.com)

\section{ARTICLE INFO :}

$\begin{array}{lll}\text { Received } & : & 26.04 .2019 \\ \text { Revised } & : & 06.05 .2019 \\ \text { Accepted } & : & 17.05 .2019\end{array}$

KEY WORDS :

Youth, Mental health

\section{HOW TO CITE THIS ARTICLE :}

Gupta, Prerna and Tiwari, Gaytri (2019). Status of mental health amongst college going youth of Udaipur district, Rajasthan. Adv. Res. J. Soc. Sci., 10 (1) : 17-21, DOI: 10.15740/HAS/ARJSS/ 10.1/17-21. Copyright@2019: Hind Agri -Horticultural Society

\begin{abstract}
Youth, defined by the United Nations as persons between the ages of 15 and 24 years, is a transitional period from childhood to adulthood, represents almost 18 per cent of the current global population. Young people often show an increase in risk-taking behaviours, such as substance misuse, use of illegal drugs, careless driving, eating disorders, unsafe sexual behaviour, crime and suicidal behaviors (Keren and Hasida, 2007). Mental health is defined as a state of well-being in which every individual realizes his or her own potential, can cope with the normal stresses of life, can work productively and fruitfully and is able to make a contribution to her or his community (WHO, 2014). Due to inexperience of life, they find easy to indulge in drug or alcohol abuse to overcome stress or problem, but it ultimately results in another psychological problems. So there is a need to address these issues and assess their mental wellbeing in order to make a better life. The present study aims to investigate the Mental health status of 360 college going youth in the age group of 19 to 22 years of Udaipur district of Rajasthan State. Simple random sampling procedure was followed to collect the data. The study was conducted in both government and private colleges. A representative sample of total 360 respondents (180 boys and 180 girls) which was further divided stream wise, that is, 120 each from arts, science and commerce was selected from undergraduate and graduate classes for the present study. Mental health battery by Singh and Gupta (2000) was administered for data collection. Frequency, percentage were used for analysis of data. Results revealed that among overall respondents majority of youth had good mental health. It was also reported that majority of youth were found to be good in emotional stability, overall adjustment, autonomy, security- insecurity and intelligence component ofmental health except self- concept where they were fell into the category of average.
\end{abstract}

